\title{
Community-Acquired Pneumonia due to Endemic Human Coronaviruses compared to 2019 Novel Coronavirus: A Review
}

\author{
Julio A. Ramirez ${ }^{1,2 *}, M D$; Ruth Carrico ${ }^{1,2}$, PhD; Rodrigo Cavallazzi ${ }^{2,5}, M D$; Leslie Beavin ${ }^{1,2}, M D ;$ Anupama Raghuram ${ }^{1,2}$, MD; Mark V.

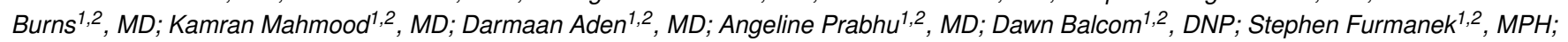 \\ Leslie Wolf ${ }^{1,2,4}$, PhD; Kenneth E. Palmer ${ }^{5}$, PhD; Mahder Tella ${ }^{1,2}$, MPH; Connor Glick ${ }^{1,2}$, MS; Forest W. Arnold ${ }^{1,2}$, DO; for the Center of \\ Excellence for Research in Infectious Diseases (CERID) Coronavirus Study Group ${ }^{2}$ \\ ${ }^{1}$ Division of Infectious Diseases, Department of Medicine, School of Medicine, University of Louisville, Louisville, KY, USA; ${ }^{2}$ Center of Excellence for Research in \\ Infectious Diseases (CERID) Coronavirus Study Group, University of Louisville, Louisville, KY, USA (see Appendix); ${ }^{3}$ Division of Pulmonary, Critical Care, and Sleep \\ Disorders Medicine, Department of Medicine, School of Medicine, University of Louisville, Louisville, KY, USA; ${ }^{4}$ Louisville Metro Department of Public Health and \\ Wellness, Louisville, KY, USA; ${ }^{5}$ Center for Predictive Medicine for Biodefense and Emerging Infectious Diseases, University of Louisville, Louisville, KY, USA
}

*j.ramirez@louisville.edu

Recommended Citation: Ramirez JA, Carrico R, Cavallazzi R, et al. Community-acquired pneumonia due to endemic human coronaviruses compared to 2019 novel coronavirus: A review. Univ Louisville J Respir Infect 2020; 4(1):Article 2. doi: 10.18297/jri/vol4/iss1/2.

\begin{abstract}
The human coronaviruses (HCoVs) are an important etiology of community-acquired respiratory tract infections. Community-acquired pneumonia (CAP) may be caused by serotypes of endemic HCoVs or highly pathogenic HCoVs.
\end{abstract}

In this review we compared clinical characteristics, management, outcomes, and infection control practices for patients with CAP due to endemic HCoVs versus patients with CAP due to 2019 novel coronavirus (SARS-CoV-2).

\section{Introduction}

There are four serotypes of $\mathrm{HCoVs}$ that are endemic and three highly pathogenic $\mathrm{HCoVs}$ (Figure 1). Endemic HCoVs cause respiratory tract infection in children and adults globally. We recently reported our experience with adults hospitalized with CAP due to endemic HCoVs in the city of Louisville, Kentucky.[1] The first cases of CAP due to highly pathogenic $\mathrm{HCoVs}$, the severe acute respiratory syndrome coronavirus (SARSCoV), were identified in China in 2002. [2] Cases of CAP due to a second highly pathogenic $\mathrm{HCoV}$, the Middle East respiratory syndrome coronavirus (MERS-CoV), were identified in Saudi Arabia and Qatar in 2012.[3, 4] More recently, cases of CAP due to the 2019 novel coronavirus (2019-nCoV) were identified in the city of Wuhan, China at the end of 2019.[5] Based on phylogeny, this new coronavirus is recognized as a sister of the SARS-CoV, and the Coronavirus Study Group of the International Committee on Taxonomy of Viruses is proposing to designate this new virus as severe acute respiratory syndrome coronavirus 2 (SARS-CoV-2).[6] The World Health Organization is now officially calling the disease COVID-19 (CO for corona, VI for virus, D for disease, and 19 for the year 2019). Having a name for the virus (2019-nCoV or SARS-CoV-2) and a different name for the disease (COVID-19) will help with the nomenclature of future coronavirus outbreaks. The spectrum of disease for patients presenting with COVID-19 is depicted in Figure 2.

In this manuscript we first compared the clinical characteristics and outcomes of patients with CAP due to endemic HCoVs admitted to hospitals in the city of Louisville [1] versus patients with CAP due to the 2019nCoV admitted to hospitals in the city of Wuhan.[7] We subsequently reviewed our current understanding of the risk factors, diagnosis, infection control practices, and management of patients with CAP due to endemic HCoVs and the 2019-nCoV or SARS-CoV-2.

\section{Clinical Presentation and Outcomes}

The demographics, comorbidities, and signs and symptoms of 42 patients hospitalized with endemic HCoVs as the only etiology of CAP from the city of Louisville [1] and the first 41 patients reported in the literature with CAP due to the 2019-nCoV from the city of Wuhan [7] are depicted in Table 1. The age distribution of both groups is depicted in Figure 3. Patients infected with the 2019-nCoVs are younger and present with less co- 


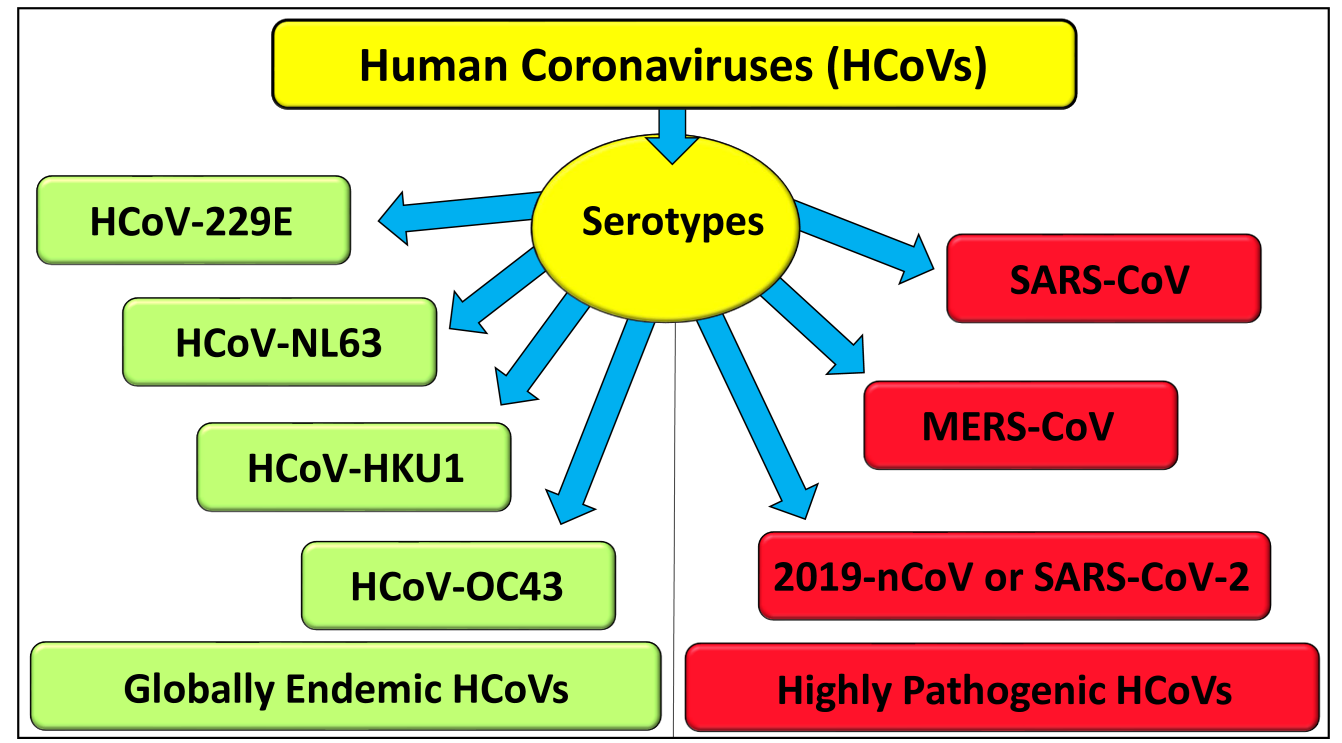

Figure 1. Serotypes of HCoVs globally endemic and highly pathogenic. SARS-CoV: Severe acute respiratory syndrome coronavirus. Abbreviations: MERS-CoV, Middle East respiratory syndrome coronavirus; 2019-nCoV, 2019 novel coronavirus; SARS-CoV-2, severe acute respiratory syndrome coronavirus 2 .

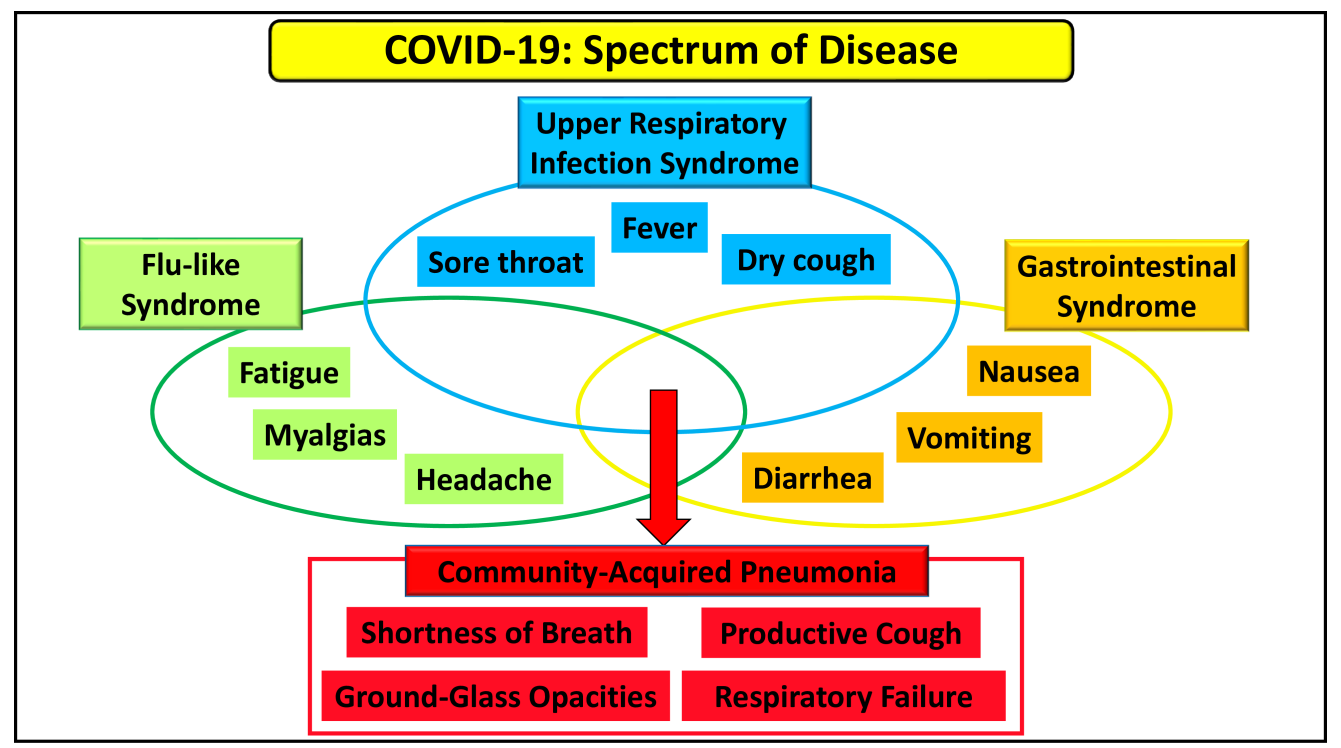

Figure 2. Spectrum of disease for patients presenting with COVID-19. 
Table 1. Demographics, comorbidities, and signs and symptoms of 42 patients with CAP due to endemic CoVs from the city of Louisville and the first 41 patients reported in the literature with CAP due to the 2019-nCoV from the city of Wuhan.

\begin{tabular}{|c|c|c|}
\hline Variable & $\begin{array}{l}\text { Louisville Endemic CoV } \\
\qquad(n=42)\end{array}$ & $\begin{array}{c}\text { Wuhan 2019-nCoV } \\
(n=41)\end{array}$ \\
\hline \multicolumn{3}{|l|}{ Demographics } \\
\hline Age, years & $71[54,82]$ & $49[41,58]$ \\
\hline \multicolumn{3}{|l|}{ Sex $(\%)$} \\
\hline Men & $18(43)$ & $30(73)$ \\
\hline Women & $24(57)$ & $11(27)$ \\
\hline Current Smoker (\%) & $9(21)$ & $3(7)$ \\
\hline \multicolumn{3}{|l|}{ Comorbidities } \\
\hline Any Comorbidity (\%) & $39(93)$ & $13(32)$ \\
\hline Diabetes (\%) & $15(36)$ & $8(20)^{\prime}$ \\
\hline Hypertension (\%) & $30(71)$ & $6(15)$ \\
\hline Cardiovascular disease (\%) & $15(36)$ & $6(15)$ \\
\hline Chronic obstructive pulmonary disease (\%) & $15(36)$ & $1(2)$ \\
\hline Malignancy or active neoplastic disease (\%) & $7(17)$ & $1(2)$ \\
\hline Liver Disease (\%) & $3(7)$ & $1(2)$ \\
\hline \multicolumn{3}{|l|}{$\begin{array}{l}\text { Signs and symptoms } \\
\text { Highest temperature, }{ }^{\circ} \mathrm{C}(\%)\end{array}$} \\
\hline$<37.3$ & $20(48)$ & $1(2)$ \\
\hline $37.3-38.0$ & $4(10)$ & $8(20)$ \\
\hline $38.1-39.0$ & $11(26)$ & $18(44)$ \\
\hline$>39.0$ & $7(17)$ & $14(34)$ \\
\hline Systolic pressure, $\mathrm{mm} \mathrm{Hg}$ & $120[103.0,133.0]$ & $125[119.0,135.0]$ \\
\hline Respiratory rate $>24$ breaths per $\min (\%)$ & $17(40)$ & $12(29)$ \\
\hline
\end{tabular}

Abbreviations: CAP, community-acquired pneumonia. Dichotomous variables are reported as frequency/total (\%); continuous variables are reported as median [interquartile range].

morbidities when compared to patients infected with endemic HCoVs. Table 2 compares the laboratory and radiographic findings of both groups. Patients with CAP due to 2019-nCoV presented with lower white blood cells count and higher elevations in liver enzymes. In both groups of patients, procalcitonin levels were low, as expected of patients with viral CAP. The presence of pulmonary infiltrates with bilateral involvement was present in almost $100 \%$ of patients in both groups. The treatments and outcomes of both groups are depicted in Table 3. In the initial report of CAP due to $2019-\mathrm{nCoV}$, the high mortality of $15 \%$ was likely a reflection of a more critically ill population of patients being initially recognized with the disease. A second case series, including 139 hospitalized patients with 2019-nCoV, reported a mortality of 4\%.[8] This mortality is similar to the one that we reported for hospitalized patients with endemic $\mathrm{HCoVs}$ of $2 \%$.

\section{Risk Factors and Diagnosis}

The incubation period of $2019-\mathrm{nCoV}$ is thought to range from 3 to 14 days, with most patients developing clinical manifestations within the first week following exposure. Since an infected person may be asymptomatic for up to 14 days, a patient with fever and/or symptoms of respiratory tract infection should be considered at risk of 2019-nCoV infection if: 1) the patient, within the prior 14 days, resided in or traveled to China, or 2) the patient, within the prior 14 days, had close contact with a confirmed or suspected case of 2019-nCoV infection. In a patient at risk of 2019 nCoV infection, the diagnosis is confirmed by performing a PCR of specimens from the upper respiratory tract (e.g. nasopharyngeal or oropharyngeal secretions) using 2019-nCoV primers.

\section{Infection Control Measures}

There are four areas of infection control practice that are relevant for the safety of healthcare workers caring for patients with CAP due to endemic HCoVs as well as the 2019-nCoV. They include early recognition and isolation, selection and use of personal protective equipment, performance of hand hygiene, and environmental infection control. The specific infection control recommendations for endemic $\mathrm{HCoVs}$ and 2019-nCoV are depicted in Table 4.

In a recent report of 138 patients hospitalized with 2019-nCoV infection, the authors estimated that nosocomial transmission of the virus may have occurred in 


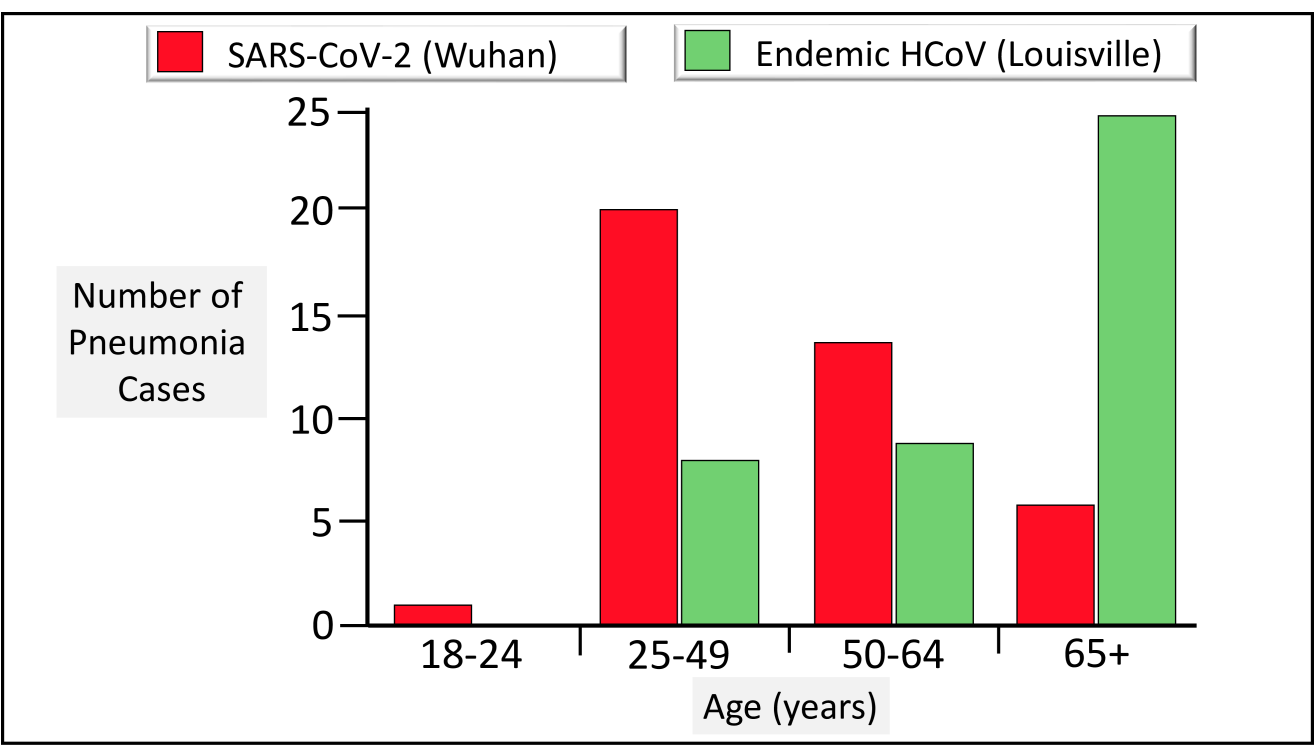

Figure 3. Age distribution of 42 patients with CAP due to endemic human CoVs from the city of Louisville and the first 41 patients reported in the literature with CAP due to the 2019-nCoV or SARS-Cov-2 from the city of Wuhan.

Table 2. Laboratory and radiographic findings of 42 patients with CAP due to endemic CoVs from the city of Louisville and the first 41 patients reported in the literature with CAP due to the 2019-nCoV from the city of Wuhan.

\begin{tabular}{|c|c|c|}
\hline Variable & $\begin{array}{l}\text { Louisville endemic CoV } \\
\qquad(n=42)\end{array}$ & $\begin{array}{c}\text { Wuhan 2019-nCoV } \\
(n=41)\end{array}$ \\
\hline White blood count per $1000 / \mu \mathrm{L}$ & $11.0[9.1,15.2]$ & $6.2[4.1,10.5]$ \\
\hline$<4$ & $2 / 41(5)$ & $10 / 40(25)$ \\
\hline $4-10$ & $14 / 41(34)$ & $18 / 40(45)$ \\
\hline$>10$ & $25 / 41(61)$ & $12 / 40(30)$ \\
\hline Platelets per $1000 / \mu \mathrm{L}$ & $229[173,266]$ & $164.5[131.5,263.0]$ \\
\hline$<100$ & $2 / 42(5)$ & $2 / 40(5)$ \\
\hline$\geq 100$ & $40 / 42(95)$ & $38 / 40(95)$ \\
\hline Albumin, g/dL & $36.0[34.0,40.0]$ & $31.4[28.9,36.0]$ \\
\hline Alanine transferase (ALT), U/L & $27[21,36]$ & $32[21,50]$ \\
\hline Aspartate transaminase (AST), U/L & $23[20,32]$ & $34[26,48]$ \\
\hline$\leq 40$ & $32 / 39(82)$ & $26 / 41(63)$ \\
\hline$>40$ & $7 / 39(18)^{\prime}$ & $15 / 41(37)$ \\
\hline Bilirubin ,mg/dL & $0.6[0.5,0.9]$ & $0.7[0.6,0.8]$ \\
\hline Potassium ,mmol/L & $4.0[3.7,4.4]$ & $4.2[3.8,4.8]$ \\
\hline Serum sodium ,mmol/L & $138[135,140]$ & $139[137,140]$ \\
\hline Procalcitonin $(\mu \mathrm{g} / \mathrm{mL})$ & $0.1[0.1,0.3]$ & $0.1[0.1,0.1]$ \\
\hline$<0.1$ & $7 / 14(50)$ & $27 / 39(69)$ \\
\hline$\geq 0.1$ to $<0.25$ & $3 / 14(21)$ & $7 / 39(18)$ \\
\hline$\geq 0.25$ to $<0.5$ & $2 / 14(2)$ & $2 / 39(5)$ \\
\hline$\geq 0.5$ & $2 / 14(2)$ & $3 / 39(8)$ \\
\hline Hypersensitive troponin, $\mathrm{pg} / \mathrm{mL}$ & $20.5[10.0,38.5]$ & $3.4[1.1,9.1]$ \\
\hline$>28$ & $12 / 28(43)$ & $5 / 41(12)$ \\
\hline Bilateral involvement of chest radiographs & $41 / 42(98)$ & $40 / 41(98)$ \\
\hline
\end{tabular}

Abbreviations: CAP, community-acquired pneumonia; CoV, coronavirus.

Dichotomous variables are reported as frequency/total (\%); continuous variables are reported as median [interquartile range]. 
Table 3. Treatment and outcomes of 42 patients with CAP due to endemic CoVs from the city of Louisville and the first 41 patients reported in the literature with CAP due to the 2019-nCoV from the city of Wuhan.

\begin{tabular}{lcc}
\hline Variable & $\begin{array}{c}\text { Louisville Endemic CoV } \\
(n=42)\end{array}$ & $\begin{array}{c}\text { Wuhan 2019-nCoV } \\
(n=41)\end{array}$ \\
\hline Shock with need for vasopressors (\%) & $3(7)$ & $3(7)$ \\
Non-invasive ventilation (\%) & $3(7)$ & $10(24)$ \\
Invasive mechanical ventilation (\%) & $3(7)$ & $2(5)$ \\
Death (\%) & $1(2)$ & $6(15)$ \\
\hline
\end{tabular}

Table 4. Specific infection control recommendations for patients infected with endemic human coronaviruses (HCoVs) and 2019 novel coronavirus (2019-nCoV) or severe acute respiratory syndrome coronavirus 2 (SARS-CoV-2).

\begin{tabular}{lll}
\hline & Endemic HCoVs & 2019-nCoV or SARS-CoV-2 \\
\hline Isolation & $\begin{array}{l}\text { Standard precautions, private room } \\
\text { not required }\end{array}$ & $\begin{array}{l}\text { Airborne isolation room providing verified negative airflow in } \\
\text { combination with contact isolation }\end{array}$ \\
$\begin{array}{l}\text { Personal } \\
\text { protective } \\
\text { equipment }\end{array}$ & Not recommended & $\begin{array}{l}\text { Barrier use (e.g., eye protection, gowns and gloves) to prevent } \\
\text { contact with body fluids, such as respiratory secretions that may } \\
\text { be projected during cough. Respirator use in accordance with } \\
\text { airborne isolation. }\end{array}$ \\
$\begin{array}{l}\text { Hand hygiene } \\
\begin{array}{l}\text { Environmental } \\
\text { disinfection }\end{array}\end{array}$ & $\begin{array}{l}\text { Alcohol-based hand rubs } \\
\text { Use of an EPA-registered disinfectant removal of gloves, alcohol-based hand rubs }\end{array}$ \\
\hline
\end{tabular}

Abbreviations: EPA, Environmental Protection Agency.

$40 \%$ of the patients.[8] They considered transmission from patient to patient in 17 patients $(12 \%)$ and transmission from patient to health care worker in 40 patients $(29 \%)$. It is important that several patients in this report were not placed in respiratory isolation at the time of hospital admission because the initial patient's complaints were related to atypical abdominal symptoms. As depicted in Figure 2, some patients may have a gastrointestinal syndrome as initial presentation of Covid-19. In these cases, the virus may be transmitted via the fecal-oral route.

\section{ICU Management}

Some parallels can be made to the prior two epidemic strains, MERS-CoV and SARS-CoV in transmission and clinical features and thus ICU management strategies implemented in those epidemics could be applied currently. Clinicians at University of Toronto described specific challenges in oxygenating patients with SARSCoV.[9] The use of oxygen therapy with aerosol humidifiers was suspected to increase the risk of droplet transmission. Additional routine ICU procedures were deemed high risk due to infection control concerns including intubation and extubation, nasopharyngeal swab, bag-valve-mask ventilation, suctioning, noninvasive positive pressure ventilation (NIPPV), and high frequency oscillation. Disconnection from the ventilator and manual bag ventilation was discouraged due to concerns for droplet spread even in cases of cardiac arrest unless an obvious mechanical failure was suspected.

Ventilator management of SARS-CoV mirrored that of acute respiratory distress syndrome (ARDS). Similar observations were made with the MERS-CoV outbreak as described by clinicians in Jeddah, Saudi Arabia.[10] Management of respiratory failure with NIPPV was strongly discouraged as it almost always lead to intubation and also carried significant risk of droplet spread.

In patients who develop ARDS leading to invasive ventilation, we consider a strategy of low tidal volume (4 to $6 \mathrm{ml} / \mathrm{Kg}$ of predicted body weight) and the use of positive-end-expiratory pressure titrated according to the requirement of oxygen. The plateau pressure should be maintained at less than $30 \mathrm{cmH} 2 \mathrm{O}$.[11] We also consider monitoring driving pressure, since higher driving pressure values have been associated with higher mortality in patients with ARDS.[12] In the setting of refractory hypoxia, other strategies should be considered such as prone position and extracorporeal membrane oxygenation.[13, 14] 


\section{Therapy}

The majority of the proposed therapies for CAP due to human coronavirus came to light during the SARS-CoV and MERS-CoV outbreaks in 2003 and 2012, respectively. Treatment options evaluated in clinical studies included antivirals, such as ribavirin, antiretrovirals such as lopinavir/ritonavir, steroids, interferon, and macrolides. In most reports, these therapies have been used in combination without a clear clinical benefit.

Remdesivir is a novel nucleotide analogue with activity against SARS and MERS-CoV in vitro and in animal studies.[15] Remdesivir was utilized as a compassionate use investigational drug in the first described US case of 2019-nCoV in January 2020. The patient had mild initial symptoms that progressed to pneumonia on the ninth day of admission, with rapid clinical improvement after treatment with remdesivir. This novel agent is being considered for further randomized clinical trials in China to establish efficacy in humans during the current 2019-nCoV outbreak. Investigators from the National Institute of Allergy and Infectious Diseases (NIAID) are preparing to test remdesivir, as well as lopinavir/ ritonavir (Kaletra), and interferonbeta for their activity against 2019-nCoV.[16]

\section{Prospect for a Vaccine}

The NIAID Vaccine Research Center is leading the efforts to develop a vaccine for the 2019-nCoV. Investigators are using a messenger RNA platform to produce the viral spike protein of 2019-nCoV. The NIAID anticipates the experimental vaccine will be ready for testing in a phase 1 trial in the coming months.[16]

\section{Conclusions}

Patients with CAP due to 2019-nCoV tend to be younger, and with less comorbidities than patients with CAP infected with endemic $\mathrm{HCoVs}$, however, the clinical presentation and outcomes for both groups of patients is similar. Optimal implementation of infection control practices is important to contain the 2019nCoV spread in the community and hospital setting. Patients hospitalized with CAP due to 2019-nCoV have a mortality of approximately $3 \%$, very similar to the mortality of hospitalized patients with CAP due to endemic HCoVs. Mortality of hospitalized patients with CAP due to 2019-nCoV is expected to decrease as new therapeutic strategies are developed.
Acknowledgements: The authors would like to acknowledge Jessica Petrey, Clinical Librarian, Kornhauser Health Sciences Library, University of Louisville, for her contribution with literature search.

Received: February 12, 2020

Accepted: February 20, 2020

Published: February 25, 2020

Copyright: (c) 2022 The author(s). This original article is brought to you for free and open access by ThinkIR: The Uni- versity of Louisville's Institutional Repository. For more information, please contact thinkir@louisville.edu. This article is distributed under the terms of the Creative Commons Attribution 4.0 International License (CC BY 4.0), which permits unrestricted use, distribution, and reproduction in any medium, provided the original author and source are credited.

Funding Source: The author(s) received no specific funding for this work.

Conflict of Interest: All authors declared no conflict of interest in relation to the main objective of this work.

\section{References}

1. Arnold FW, Burns MV, Mahmood K, et al. Endemic human coronaviruses in hospitalized adults with communityacquired pneumonia: Results from the Louisville Pneumonia Study. Univ Louisville J Respir Infect 2020; 4(1):Article 1. doi: 10.18297/jri/vol4/iss1/1.

2. Ksiazek TG, Erdman D, Goldsmith CS, et al. A novel coronavirus associated with severe acute respiratory syndrome. N Engl J Med 2003; 348(20):1953-66. doi: 10.1056/NEJMoa030781. PMID: 12690092.

3. Zaki AM, van Boheemen S, Bestebroer TM, Osterhaus $A D$, Fouchier RA. Isolation of a novel coronavirus from a man with pneumonia in Saudi Arabia. N Engl J Med 2012; 367(19):1814-20. doi: 10.1056/NEJMoa1211721. PMID: 23075143
4. Corman VM, Eckerle I, Bleicker T, et al. Detection of a novel human coronavirus by real-time reverse-transcription polymerase chain reaction. Euro Surveill 2012; 17(39). doi: 10.2807/ese.17.39.20285-en. PMID: 23041020.

5. Zhu N, Zhang D, Wang W, et al. A novel coronavirus from patients with pneumonia in China, 2019. N Engl J Med 2020; 382(8):727-33. doi: 10.1056/NEJMoa2001017. PMID: 31978945 .

6. Gorbalenya AE, Baker SC, Baric RS, et al. Severe acute respiratory syndrome-related coronavirus: The species and its viruses - a statement of the Coronavirus Study Group. bioRxiv 2020:2020.02.07.937862. doi: 10.1101/2020.02.07.937862.

7. Huang C, Wang $\mathrm{Y}, \mathrm{Li} \mathrm{X}$, et al. Clinical features of pa- 
tients infected with 2019 novel coronavirus in Wuhan, China. Lancet 2020; 395(10223):497-506. doi: 10.1016/s01406736(20)30183-5. PMID: 31986264.

8. Wang D, Hu B, Hu C, et al. Clinical characteristics of 138 hospitalized patients with 2019 novel coronavirus-infected pneumonia in Wuhan, China. JAMA 2020; 323(11):1061-9. doi: 10.1001/jama.2020.1585. PMID: 32031570.

9. Lapinsky SE, Hawryluck L. ICU management of severe acute respiratory syndrome. Intensive Care Med 2003; 29(6):870-5. doi: 10.1007/s00134-003-1821-0. PMID: 12739014

10. Al-Hameed F, Wahla AS, Siddiqui S, et al. Characteristics and outcomes of Middle East respiratory syndrome coronavirus patients admitted to an intensive care unit in Jeddah, Saudi Arabia. J Intensive Care Med 2016; 31(5):344-8. doi: 10.1177/0885066615579858. PMID: 25862629.

11. Brower RG, Matthay MA, Morris A, Schoenfeld D, Thompson BT, Wheeler A. Ventilation with lower tidal volumes as compared with traditional tidal volumes for acute lung injury and the acute respiratory distress syndrome. $\quad \mathrm{N}$ Engl J Med 2000; 342(18):1301-8. doi: 10.1056/nejm200005043421801. PMID: 10793162.
12. Amato $M B$, Meade $M O$, Slutsky $A S$, et al. Driving pressure and survival in the acute respiratory distress syndrome. N Engl J Med 2015; 372(8):747-55. doi: 10.1056/NEJMsa1410639. PMID: 25693014.

13. Guérin C, Reignier J, Richard JC, et al. Prone positioning in severe acute respiratory distress syndrome. $\mathrm{N}$ Engl J Med 2013; 368(23):2159-68. doi: 10.1056/NEJMoa1214103. PMID: 23688302.

14. Peek GJ, Mugford M, Tiruvoipati R, et al. Efficacy and economic assessment of conventional ventilatory support versus extracorporeal membrane oxygenation for severe adult respiratory failure (CESAR): A multicentre randomised controlled trial. Lancet 2009; 374(9698):1351-63. doi: 10.1016/s0140-6736(09)61069-2. PMID: 19762075.

15. Sheahan TP, Sims AC, Graham RL, et al. Broadspectrum antiviral GS-5734 inhibits both epidemic and zoonotic coronaviruses. Sci Transl Med 2017; 9(396). doi: 10.1126/scitranslmed.aal3653. PMID: 28659436.

16. National Institute of Allergy and Infectious Diseases. Developing therapeutics and vaccines for coronaviruses. Available at: https://www.niaid.nih.gov/diseases-conditions/ coronaviruses-therapeutics-vaccines. Accessed 8 February 2020. 


\section{Appendix: Center of Excellence for Research in Infectious Diseases (CERID) Coronavirus Study Group}

\section{CERID Leadership}

Julio Ramirez, MD, Executive Director

Forest Arnold, DO, Associate Director

Ruth Carrico, PhD, Director of Epidemiological Research

Leslie Wolf, PhD, Director of Laboratory Research

Senen Peña, MD, Director of Research Operations

Emily Just, MA, Director of Administrative Operations

\section{CERID Scientific Advisory Board}

Rodrigo Cavallazzi, MD

Anupama Raghuram, MD

Leslie Beavin, MD

Mark Burns, MD

Barbara Wojda, MD

Julio Ramirez, MD (Executive Director)

\section{CERID Operating Units}

Implementation Unit

Amr Aboelnasr (Lead)

Vidyulata Salunkhe

Daniya Sheikh

Prashant Tripathi

Mohammed Abbas

Ahmed Abdelhaleem

Mutasem Abuhalaweh

Ahmed Adel

Khaled Alsweis

Omar Altantawi

Ibrahim Asha

Kareem Ashraf

Pradeepthi Badugu

Marilhia Cornejo

Farah Daas

Deepti Deepti

Rafik Elbeblawy

Sherin Elgohary

Athar Eysa

Omar Fahmy

Rolando Cordoves Feria

Islam Gadelmoula

Ahmed Gana

Evelyn Exposito Gonzalez

Basel Haddad

\author{
Marjan Haider \\ Dina Haroun \\ Mohamed Ismail \\ Bibodh Jung Karki \\ Dilip KC \\ Ahsan Masood Khan \\ Simra Kiran \\ Dana Mantash \\ Ahmed Mowafy \\ Pavani Nathala \\ Ahmed Omran \\ Pranav Pillai \\ Sravan Ponnekanti \\ Ramya Praveen Kumar \\ Edisley Reyes Fundora \\ Balachandran Rishinaradamangalam \\ Harideep Samanapally \\ Balaji Sekaran \\ Ayesha Shameem \\ Ahmed Ali Shebl \\ Nishita Tripathi \\ Darmaan Aden, MD (Fellow) \\ Kamran Mahmood, MD (Fellow) \\ Angeline Prabhu, MD (Fellow)
}

Data Management Unit

Mahder Tella, MPH (Lead)

Biostatistics Unit

Stephen Furmanek, MPH (Lead)

Mahder Tella, MPH

Connor Glick, MS

Research \& Diagnostic Laboratory Unit

Leslie Wolf, PhD (Lead)

Biorepository Unit

Subathra Marimuthu, PhD (Lead)

Quality Assurance Unit

Mohammed Tahboub (Lead)

Iqbal Ahmed

Duremala Duremala

Raghava Sekhar

Sahaj Hardeep Singh

Regulatory \& Compliance Unit Maria Hill (Lead) 


\section{Clinical Research Internship}

Morgan Stanley (Lead)

Mohamed Abdelnabi

Mahmoud Abdelsamia

Yousra Alghalban

Arshdeep Batth

Arpan Chawala

Lakshmi Cherukuwada

Arashpreet Chhina

Satya Durugu

Mostafa El Razzaz

Salman Elgharbawy

Durgaprasad Gadireddi

Reham Gendi

Shivam Gulati

Zahid Imran

Divya Menghani

Jeremiah Olabiyi

Lucia Puga Sanchez

Nida Qadir

Adnan Qureshi

Gowthami Ramineni

Ashraf Rjob

Syed Shah

Hammad Tanzeem

\section{Medical Writing Unit}

Forest Arnold, DO (Lead)

Informatics Unit

William Mattingly, PhD (Lead)

Matthew Grassman

Rakhi Shah

Gregory Lindauer

Marketing Unit

Tonya Augustine (Lead)

Tessa Chilton

Trevor Bosley

University Outreach Unit

Ruth Carrico, PhD (Lead)

Community Outreach Unit

Dawn Balcom, PhD (Lead)

Administration Unit Emily Just, MA (Lead)

Eman Abbas

Morgan Stanley

Catherine Bryan

Financial Unit

Dan Kapp (Lead) 